\title{
HIV and injecting drug users in Vietnam: An overview of policies and responses
}

\begin{abstract}
The HIV epidemic in Vietnam is fuelled by injecting drug use. Since HIV emerged, because of a law enforcement focused drug policy and response, Injecting Drug Users (IDUs) frequently experience drug detention and compulsory treatment. It has taken more than a decade to shift the focus from punitive to liberal policies. This overview presents a brief discussion on policies, responses and experiences to identify implications. Related literature including government policies, peer-reviewed articles and reports has been reviewed. The HIV epidemic in IDUs accelerated rapidly in an environment characterised by a lack in understanding and recognition of significance. There was limited leadership and weak direction to implement an even countrywide response. Policies and responses gradually shifted to a harm reduction approach and recognised the need for harmonization, relating common features of drug and HIV. The review identifies that government leadership is crucial for supportive policies and long-term strategies. A multi-sectoral collaboration and continuous resource allocation with national priorities is essential to impact on the epidemic. In this review the context of these issues in policies and responses were highlighted and discussed which gradually can lead towards the development of a substantial response for the drug use driven HIV epidemic in Vietnam.
\end{abstract}

\section{Key words}

HIV; Injecting drug user; Vietnam; Policies; Responses; Harm Reduction 


\section{Introduction}

Globally injecting drug use accounts for a high proportion of new HIV infections driving the national epidemic in many countries where HIV prevalence among Injecting Drug Users (IDU) ranges from 5\% (Eastern Europe) to 28\% (Asia). (UNAIDS 2013). In Vietnam, injecting drug use accounts for nearly two-thirds of all HIV cases (Ministry of Health 2011) and thus fuel the HIV epidemic with an infection rate of almost $20 \%$, reaching more than $50 \%$ in some provinces (Ministry of Health 2011). The problem of drug abuse and trafficking in Vietnam is long-standing, primarily due to its close location to the infamous 'Golden Triangle', the opium producing region bordering Myanmar, Thailand and Laos and thus predates the HIV epidemic among IDUs (Poshyachinda 1993; Reid \& Costigan 2002). Vietnam is the preferred transit route for much of the opium produced in this region and as a result, some provinces in the north became heavily engaged in the heroin entry route from Laos (Beyrer et al. 2000; Quan, Hien, \& Go 2008). Historically, opium had reached northern Vietnam in the early 19th century, soon after British opium began flooding China from Myanmar (McCoy 1991). Opium was cultivated and it was supported by the indigenous lifestyle which includes eating and smoking as part of regular daily activities among ethnic communities in the northern highlands (UNODC 2003). Although such practices were accepted and widespread in mountainous regions of northern Vietnam, in other parts, especially in lowland areas it was not common (UNODC 2003). In the past there were a number of efforts to prevent the production and consumption of opium in this part of Vietnam (DEA 2003; UNAIDS \& UNODCCP 2000). As a result, production declined; however, the consumption of heroin still increased dramatically (Nguyen \& Scannapieco 2008). Data from a survey on drug situation by the Ministry of Labour, Invalids and Social Affairs (MOLISA) show that nearly two-thirds of the drug using population belongs to the northern mountainous region (Nguyen \& Scannapieco 2008). Later, Vietnam saw the transition, execution and replication of a number unsuccessful efforts relating to the production, consumption and trafficking of opium. Moreover, economic deregulation commenced after 1986 resulting in the introduction of market oriented policies that facilitated the rapid growth of drug use behaviours among the young Vietnamese population, especially in urban areas of the country (Quan et al. 2008; Rekart 2002).

In 1990, the first HIV case was reported in the southern part of Vietnam (Hien \& Wolffers 1994). In 1993 alone, 945 cases were reported, of which $87 \%$ of sero-positive persons were 
IDUs (Hien \& Wolffers 1994; Nguyen et al. 1999). Later, the country observed a rapid spread of the HIV infection among IDUs and expansion from south to north (Chung, $\mathrm{Vu}, \&$ Dondero 1998; Vu 2001). Injecting practices together with sharing of needles/syringes (N/S), attendance in shooting galleries and absence of risk reduction measures fuelled the rapid HIV transmission (Hien et al. 2001; Quan, Chung, \& Abdul-Quader 1998). Contemporaneous with the progress of the epidemic, the government had, with considerable foresight, established and continually strengthened the HIV surveillance system to properly monitor the epidemic (Hien \& Wolffers 1994; Quan, Chung, Long, \& Dondero 2000). By the middle of 1995 injecting 'blackwater', a concoction derived from mixing the residue of smoked opium, became widespread in Vietnam including in the lowlands of the north and south, and this was later characterised as the urbanization of drug use (UNODC 2003). The percentage of drug population who belonged to the northern mountainous region dropped from two-thirds to less than one-third and started spreading through lowlands of north and south (Nguyen \& Scannapieco 2008). By the end of the 1990s, the HIV prevalence among IDUs had grown rapidly because of frequent needle/syringe sharing and usage of common water containers (Quan et al. 2000). Consequently, the country experienced the twin epidemics of heroin injecting and HIV among IDUs (Cohen 2003).

These two issues of drug control and HIV prevention were originally considered separately in Vietnam (Nguyen, Nguyen, \& Trinh 2004) and the policies and related responses for the injection drug use linked epidemic evolved in a legally conflicting environment (Reid \& Higgs 2011). The need for a timely response, including needle/syringe distribution supported by well formulated policies has been identified as critical to develop a public health approach (Lindan et al. 1997) and such an approach widely known as Harm Reduction (HR) which supports a set of policy, program or intervention to promote safe practice and reduce the harm by free distribution of needle/syringe and other injecting equipment to the IDUs, would no doubt have been effective in controlling the epidemic situation (Marlatt 1998). However, despite concrete scientific evidence that the injection driven HIV epidemic could be controlled, the country did not introduce the HR program in a timely manner. As a consequence, the HIV epidemic continued to progress, affecting young IDUs (Vietnam Commission for Population Family and Children 2007) and reaching as high as $89.4 \%$ in parts of one northern province (Quan et al. 2000). For more than a decade the country witnessed a confusing uneven response, with inconsistent policies in place to tackle HIV 
epidemic in IDUs, until the policy environment changed dramatically and enabled the implementation of a public health friendly HR approach (Nguyen et al. 2010).

A noteworthy policy transformation shifted the response to the injection driven epidemic from the philosophy of punishment by treating it as 'social evil', to treatment by identifying it as a 'health problem'. The need for a critical analysis of existing policies was strenuously argued (Hammett et al. 2007; Nguyen \& Scannapieco 2008; UNAIDS \& UNODCCP 2000). Over the years, the available literature presents policy analysis according to themes (such as actors, contents), discussion of the process of developing HIV policy that supports HR programs (Nguyen et al. 2010), explanation for a positive change (Hammett et al. 2008), and highlights remaining challenges and issues for further coordination (Vuong, Ali, Baldwin, \& Mills 2012). However, little is reported analysing the responses to the drug use driven HIV epidemic. Little also is published highlighting the experiences of the subsequent responses in the progression from a punitive to a public health approach supportive of HR principles for them. Henceforth, this overview tries to fill up a crucial knowledge gap by presenting policy issues together with experiences of implementation practice emerged from the early stage. Furthermore, our discussion highlights issues of contradictions which still exist and argue the need to address immediately so that Vietnam moves further in responding to the drug use driven HIV epidemic.

Nonetheless, the rapidly increasing injection drug use driven HIV epidemic in Vietnam and related policy responses are crucial and could be informative for other countries with a similar scenario. This review discusses the policy environment in order to identify implications and provides consideration of critical issues helpful at an early stage for HIV prevention among IDUs. Furthermore, this review considers the implementation process of responses initiated, where necessary, in different provinces with support from international organizations despite the absence of an enabling environment. Such processes played a significant early role in generating a supportive change in policy. Lastly, Vietnam is noteworthy as an example of a developing country in terms of the speed of progress and development of substantial HR programs for IDUs for HIV prevention, after the delayed formal acceptance of HR principles. 


\section{Methods}

\section{Document identification and selection}

The present overview focuses on policy review and relies on a number of policy related documents covering HIV and drug use issues, at a primary level, including government Policies, Laws, Decisions, Decrees, Ordinances, Conclusions, Directives (issued by the Communist Party); and at a secondary level, a number of peer-reviewed articles showing policy analysis on HIV and drug use in Vietnam. Lastly at a tertiary level different reports from government and non-governmental organizations showing different inter-related issues in HIV and drug such as survey findings, policy implications, progress reports. Accordingly a multi-stage search strategy was adopted, to gather relevant data for this overview.

In stage one, we identified related literature including government policies, peer-review articles and progress reports of national and international organizations to conduct a review (Ahmed, Nguyen, Huong, Lee, \& Stewart 2014). A systematic search was conducted using relevant key words such as HIV/AIDS, Injecting Drug User, Vietnam, risk behaviour in different combinations. Griffith University Library Database including PubMed, ProQuest, Science Direct was used to retrieve documents published since 1995 onwards. Our search generated a total of 674 records out of which a total of 55 peer-review articles were selected following inclusion (relevant) and exclusion (duplicate, irrelevant) criteria. Out of which 50 focused on risk behaviours, harm reduction and other responses in IDUs and Female Sex Workers (FSWs) and 5 highlighted the policy issues. Additionally, 15 reports from government and non-government organizations were selected to contextualise the findings and gather process oriented deeper insights (Ahmed, Nguyen, Huong, Lee, \& Stewart 2014). In this present overview, out of those previously identified literature, we refer back to 15 peer-review articles and 10 reports which discussed responses and policy related issues.

In stage two a number of policy documents on HIV and drug was selected to conduct a policy review. Many of the policy documents related to HIV prevention and drug control in Vietnam have already been identified (Hammett et al. 2008; Jardine, Crofts, Monaghan, \& Morrow 2012; Nguyen et al. 2010) and critically analysed (Reid \& Higgs 2011; Vuong et al. 2012). A discussion was held among research team members as well as key personnel in Vietnam Authority of HIV/AIDS Control (VAAC) to select relevant policy documents (as of 
December, 2013). Under the stage two we refer to previous findings on policy analysis (Hammett et al. 2008; Jardine, Crofts, Monaghan, \& Morrow 2012; Nguyen et al. 2010; Reid \& Higgs 2011; Vuong et al. 2012), link our findings from 10 selected policy documents and lastly reflect on the recent development (Amon et al. 2013; Baldwin 2013; Dorabjee 2012; Government of Vietnam 2011a, 2012; Human Rights Watch 2012; UNAIDS 2011) to present an evolvement of HIV and drug related response in Vietnam.

In stage three an additional manual search was conducted to enrich findings and contextualise some previously unexplored key issues in HIV and drug. References to recent publications relating to HIV and drugs in Vietnam guided this search process. Discussion among team members for analysing content, suitability and richness in information with current findings facilitated the inclusion of these additional documents. After several attempts, consensus was achieved to include another 15 peer-review articles and 10 reports from government and nongovernment organizations.

Validity, reliability \& analysis

Finally, after selection by phases, a total of sixty documents (30 peer-review articles, 20 reports and 10 policy documents), was included in this overview. Inclusion of the both qualitative and quantitative data broadens the scope to reflect a number of issues (Brownson, Chriqui, \& Stamatakis 2009). The review was conducted using Walt \& Gilson's (1994) framework where the context, content, and process were identified and reviewed. The nonpeer reviewed documents (reports of government and non-government) represent a discussion on the data collection and reporting system which qualify as trustworthy findings in context of Vietnam. Furthermore, these documents pass different layers of advisory board meeting, consultation, and dissemination which further qualify as substantial resources in country context especially countries having low accessibility of resources.

\section{Results}

Results from this overview were highlighted by decades: decade one (1991-2000) and decade two and onwards (2001-2013). Summary table and figure showing policy context as well as milestones in major responses with remarks were added. 
In Vietnam, drug use and sex work are considered illegal and the drug users and sex workers are officially treated as 'social evils' (Le Truong et al. 2000; UNAIDS \& UNODCCP 2000). Since the beginning of 1990, the early response for the prevention of the HIV epidemic was associated with proscription of both IDUs and FSWs (Dorabjee 2012; Rekart 2002). The 'National Constitution of the Socialist Republic of Vietnam' in 1992 (The National Assembly of Vietnam 1992) and the 'National Assembly Resolution' in 1993 (The National Assembly of Vietnam 1993) provided the basis for the 'social evil' approach (Nguyen et al. 2010) which included a set of severe measures against IDUs such as forced detention and compulsory drug treatment in correction centres (Hammett et al. 2008; Le Truong et al. 2000). A number of residential drug treatment centres were established for treating the IDUs with such centres being known as '06 Centres' (Tarantola et al. 2009). Although these centres are supposed to provide drug treatment and other services such as social education, post rehabilitation; however, they completely rely on the old system of re-education through labour which includes forced therapeutic labour and regular exercise to recover health and labour skills (Human Rights Watch 2011). As a result, IDUs who are released from these centres lack in essential post-rehabilitation coping mechanisms and face challenges to transition back into the society (UNAIDS \& UNODCCP 2000; WHO 2009). As a consequence, neither IDUs nor FSWs are enough skilful to re-integrate within the community, nor does the wider community accept them willingly; typically IDUs encounter difficulty coping with living in mainstream society. Overall, the treatment in these centres has been characterised as ineffective with a hovering high rate (80-90\%) of relapse, causing the drug use problem to persist (WHO 2009). The majority of the detainees in these centres are young and sexually active, with many already infected with HIV (Vu 2001; WHO 2009).

In 1995, the 'Ordinance on the Prevention and Fight Against HIV/AIDS Infection' strengthened the ongoing law enforcement measures over the drug problems (The National Assembly of Vietnam 1995) and was reinforced by two other related policy documents, the 'Ordinance of Policy Violations of the National Assembly' and 'Directive No. 52' (of the Communist Party) (Vuong et al. 2012). Until the end of the 1990s, the government continuously strengthened law enforcement measures and later initiated mandatory HIV testing for incarcerated IDUs and other key population groups ( Vu 2001). However, drug control efforts initiated by the national authority in Vietnam proved ineffective (Devaney, Reid, \& Baldwin 2006) and drug use behaviour continued with increased sharing of 
needles/syringes, resulting in a high HIV prevalence among IDUs (Quan et al. 2000). In response to the rising prevalence, by the end of the 1990s (UNAIDS \& UNODCCP 2000), the government launched large-scale information campaigns, mandatory HIV testing in the '06 centres', and extended the residential treatment period for the IDUs up to five years in selected provinces (Nguyen et al. 2010). This was, however, without strengthening the national response by scaling-up best practice among the most affected population (UNAIDS \& UNODCCP 2000). The campaign on 'social evils' continued, resulting in stigmatisation among vulnerable populations which hampered the implementation of existing interventions (Khoat, West, Valdiserri, \& Phan 2003; Maher 2004).

Through the 1990s, but from a different perspective to the government's law enforcement efforts, a number of pilot HR program initiatives with financial and technical assistance from international organizations focusing on peer education, low cost condom promotion and needle/syringe distribution were undertaken sporadically at provincial level. Also, limited scale methadone-based substitution treatment was provided to prevent HIV transmission among IDUs (Hammett et al. 2008; Quan et al. 1998; Quan et al. 2000; UNAIDS \& UNODCCP 2000; Vu 2001; Walsh, Gibbie, \& Higgs 2008). Despite strict rules on needle/syringe distribution, some local and provincial authorities allowed for some flexibility and replicated HR initiatives, although they faced enormous difficulties during implementation (Reid \& Costigan 2002). For example, the Save the Children Fund initiative in 1993, in a detoxification centre in Ho Chi Minh (HCM) city was particularly remarkable (Crofts et al. 1998). Another exemplary intervention was initiated under the Global Program on AIDS by the World Health Organization (WHO) to prevent HIV among IDUs including outreach education and needles/syringe distribution (Abdul-Quader, Vu Minh, \& O'Reilly 1999; Quan et al. 1998). In 1996-97, the National Institute of Mental Health started smallscale Methadone Maintenance Therapy (MMT) in Hanoi (Devaney et al. 2006). An early evaluation of these operational peer education activities reported very limited coverage and unevenly distributed disregarding the need of higher peer educators in the high HIV burden provinces (Khoat, West, Valdiserri, \& Phan 2003).

The implementation of these projects was not only timely because of the rising HIV prevalence among IDUs (Quan et al., 2000), but they also represented an early opportunity to introduce the concept of HR to the staff members in '06 centres' as a standard part of training. Although the projects were initiated to support the philosophy of drug prevention, 
they could also play an early intermediary role whereby they would have been conducive to an effective response to the HIV epidemic, at later stage. Unfortunately, these efforts did not extend beyond pilot phase and were short-lived for a number of reasons, particularly because they raised direct policy conflicts (Devaney et al. 2006; Hien, Giang, Binh, \& Wolffers 2000). The literature of the 1990s shows that these HR projects were typically small-scale and had interrupted implementation due to frequent police crackdowns or raids (Reid \& Costigan 2002; Reid \& Higgs 2011). Another major obstacle, during pilot implementation was that the outreach workers wore a uniform which made identification easy for police when they were distributing needles/syringes at local shooting galleries (Hien et al. 2000; Nguyen et al. 2004).

\section{Responses through second decade and onwards: 2001-2013}

The period 2001-2005 was characterised by competing interests in HIV prevention and drug control identified in conflicting policy directions. In 2000, the National Assembly of Vietnam, for the first time, passed the comprehensive law on 'Narcotic Drugs Prevention and Suppression' (UNODC 2005). This newly introduced drug law although recognised the prevalence of drug use as social problem, continued to maintain the system of compulsory drug treatment and treat drug users as a 'social evil' (The National Assembly of Vietnam 2000b). Consequently, the action plan focused on law enforcement measures for detention, treatment and rehabilitation (The National Assembly of Vietnam 2000a). In 2002, Government 'Decree No. 56' further stressed family and community detoxification for IDUs (Government of Vietnam 2002). Later, MOLISA strengthened law enforcement activities for the implementation of drug laws. Traditional strategies such as controlled deliveries, undercover investigations and the use of confidential informants were often adopted during implementation (DEA 2003). In 2003, the National Assembly of Vietnam enacted 'Resolution No. 16' relating to drug treatment and detoxification services (The National Assembly of Vietnam 2003) which resulted in an extension of the treatment period, in selected provinces, for up to six years (WHO 2009). IDUs were kept locked for additional periods in these centres in the name of drug rehabilitation and vocational training (Khuat 2007). The network of treatment and detoxification centres expanded rapidly throughout the country and although it achieved the target of treating IDUs through these centres, it did not reduce drug related problems in the country (Devaney et al. 2006). However, the implementation of existing fragile interventions among IDUs was seriously affected (Maher 2004) and IDUs were highly stigmatised (Devaney et al. 2006; Ngo, Schmich, Higgs, \& 
Fischer 2009). MOLISA played key role in managing and implementing such law enforcement responses while the rising HIV prevalence in IDUs created opportunity for Ministry of Health $(\mathrm{MOH})$ to coordinate with MOLISA relating treatment and technical matters and provide basic health services in centres. However, the engagement of $\mathrm{MOH}$ in responding drug treatment and HIV epidemic in IDUs was outperformed by the lack of a policy support.

In 2004, before further escalation of the epidemic and as a result of continuous policy advocacy by local, national and international supporters, the country dramatically approved the first national HIV strategy, accepting HR principles for IDUs (Government of Vietnam 2004). This strategy has been much acclaimed, due to its comprehensiveness in covering international best practice and having a long-term vision with far reaching objectives (BBC Monitoring Asia Pacific 2005). Until this strategy was put in place, the implementation of the needle/syringe exchange and condom distribution programs were illegal in Vietnam.

Despite the absence of nationally endorsed HR programs from the outset, the post 2000 period has been associated with the development of some noteworthy HR projects, with support from international funding organizations (Devaney et al. 2006; Hammett, Kling, Johnston, Liu, \& et al. 2006; IHRD 2008; Vu 2001). Of these, two cross-border initiatives with China and Cambodia focusing respectively on IDUs and FSWs were exemplary, highlighting joint implementation across international borders (Vietnam Commission for Population Family and Children 2007; Walsh et al. 2008). The cross-border initiative for IDUs between northern Vietnam and southern China has successfully reduced the HIV prevalence and estimated an overall low incidence among new injectors (of less than three years duration) (Des Jarlais et al. 2007). A major factor which contributed was its high coverage (60-65\%) with comparatively easy access to safe injecting equipment (88 needle/syringe distribution per IDU/year) (Hammett, Kling, Johnston, Liu, \& et al. 2006). Furthermore, promising findings from the evaluation of this project raised evidence informed issues for policy advocacy (Hammett et al. 2007) and contributed to the development of supportive policies (Hammett et al. 2008).

Later, the first large-scale HR program of the country entitled 'Preventing HIV in Vietnam Project (PHP)' supported by the UK Department of International Development (DFID), was initiated which was built upon the continuous experience of small-scale initiatives between 
1990 and 2000 (VAAC/WHO 2009). The PHP became noteworthy in two ways; firstly, in terms of wider needle/syringe distribution, condom promotion, STI treatment and capacity building; and secondly, it supplemented a number of small-scale harm reduction programs in selected provinces which resulted in rapid expansion throughout the country (Government of Vietnam 2010b; VAAC/WHO 2009). Consequently, the coverage of HR program extended from 21 provinces to 42 provinces including the high HIV burden provinces. The technical and managerial capacity of these projects at national and provincial level was initially weak (Khuat 2007), and required effective coordination because of its early stage (WHO 2005). As a result, during this period a number of international organizations provided support to strengthen the capacity of the provincial level responses (IHRD 2008).

The period 2005-2010 has been characterised by strong leadership and political commitment (Khuat 2007) which resulted in the development of an overall enabling environment for the implementation of HR programs (Government of Vietnam 2010b). Firstly, in 2005, 'Directive No. 54' of the Communist Party replaced the older 'Directive No. 52' (1995) showing a positive change in the policy orientation of the central leaders (Communist Party of Vietnam 2005). The National Assembly of Vietnam realised the necessity for change and enacted the law on 'HIV/AIDS Prevention and Control' in 2006 following lengthy parliamentary debates (Vuong et al. 2012). The HIV law removed existing barriers in the field level implementation of HR projects and facilitated for HIV testing, care and treatment. These policy documents greatly supported the national response by a significant resource allocation for HIV testing, counselling and antiretroviral (ARV) treatment (WHO 2005). As a result the provision of HIV testing as well as the number of IDUs on treatment increased rapidly during this period (Government of Vietnam 2012; Khuat 2007). Later, in 2007, the Government issued 'Decree 108' for guiding the implementation of HIV law which included a detailed plan of action highlighting a multi-sectoral response (Government of Vietnam 2007). The Vietnam Authority of HIV/AIDS Control (VAAC) under the MOH was established and strengthened as a single coordinating authority (Government of Vietnam 2005). Gradually a visible role of MOH continues to appear in drug and HIV response but issues for multi-sectoral collaboration remained a challenge.

Although the HR program for IDUs was supported and legally endorsed by the above policies, there was, however, a missing link between drug control and HIV prevention, until the amendment of the drug law in 2008 linking with the law on HIV (Hammett et al. 2008). 
Furthermore, the revised version shifted the focus from criminal offence to administrative violation. In spite of such progression in HR, other important components identified in the UNAIDS comprehensive program package such as MMT were not officially incorporated in HIV response (UNAIDS 2013). Later in 2008, permission was granted to pilot the national MMT program as the substitution treatment in two provinces (Nguyen, Nguyen, Pham, Vu, \& Mulvey 2012), subsequently expanded to other provinces (Jardine, Thi Nguyen, \& Khuat 2012). In 2010, the Government planned to achieve national coverage by expanding the MMT program to 30 provinces and treating 80,000 IDUs (Asia News Monitor 2010; Government of Vietnam 2011a; Long et al. 2010; Nguyen et al. 2012). Lastly, the 'Penal Code' was amended by removing 'Article 199' which criminalised IDUs and which then provided a legal basis for treating IDUs as patients (National Assembly of Vietnam 2009). By the end of 2010, Vietnam had progressed remarkably in implementing HR programs, with a newly developed strong commitment to a long-term vision for developing a substantial response to tackle the problem of the injection driven HIV epidemic (Government of Vietnam 2012; UNAIDS 2011). However, in terms of resource allocation, all these HR activities were completely dependent on external funding support whereas the majority of the national resources were invested in treatment through drug detention centres. In 2009-10 roughly US\$ 266.6 million was used for HIV in Vietnam where almost three-fourths $(73.7 \%)$ came from international donors and less than one-third (31\%) resources were invested for the IDUs (UNAIDS 2012). Recent economic development as middle income country, has meant that international funding has reduced and Vietnam faces the funding challenge for HIV response known as middle income effect on HIV/AIDS in Vietnam (Morales 2013).

Recent progress (2011-2013) has been positive showing a political commitment and motivation. The National Committee on AIDS, Drugs and Prostitution Control and Prevention has been restructured for better multi-sectoral collaboration, and the respective committees both at provincial and district levels have been strengthened (Government of Vietnam 2012). A number of new policies have been enacted and amended together with a new national HIV and drug control strategy with a long-term vision (UNAIDS 2011) thus facilitating the implementation of the HR program at-scale in the country. The need for a smooth coordination between three key Government organizations involved with drugs and HIV (such as Ministry of Public Security, MOLISA, and MOH) was recognised for the practical development of multi-sectoral collaboration (Baldwin 2013). In June 2012, the National Assembly of Vietnam voted to close the traditional rehabilitation centres for the 
FSWs, which may indicate consideration for a new direction in terms of similar rehabilitation centres for IDUs (Edington \& Brayer 2013). A shift appears to be underway for an effective transition from compulsory drug treatment to a voluntary and community-based system (Xinema \& Davis 2014; Government of Vietnam 2011b). The approval of Decision on Drug Rehabilitation Renovation Plan 2013-2020 recognizing drug dependence as a medical problem is another indicator of progress towards a health focused response and scaling down the system of compulsory drug treatment (Government of Vietnam 2013). This provides an opportunity for the social work profession in terms of long-term practical rehabilitation (Government of Vietnam 2010a); a holistic approach for the MMT program (Government of Vietnam 2011a; Nguyen et al. 2012); and providing ARV treatment through the '06 centres'. Most importantly, it allows for the inclusion of an HIV targeted program under the state budget to supplement the funding shortfall, which clearly highlights the willingness of the Government to continue HR interventions for IDUs (Government of Vietnam 2012). A summary of policy context of major responses (based on this review) with key features and milestones in drug and HIV responses are presented in Table 1 and Figure 1 respectively.

\section{Discussion}

\section{Policies and responses}

The introduction of HR programs with a preferred combination (such as needle/syringe, condom, and bleach distribution) is controversial and poses numerous implementation challenges (Institute of Medicine 2005). As a result, many countries delay its introduction, are very slow to expand and are reluctant to include the necessary components of HR to respond to the HIV epidemic in IDUs (Wodak 2006). Unlike the slow pace of response, however, the epidemic itself rapidly progresses, in particular affecting the IDU community. Vietnam provides an example of such repeated rejection of HR policy focused response and late introduction, while also highlighting the rapid development of an enabling environment by quick approval and enactment of related policies and legal procedures in a short time. The lessons learned in this process concern overlapping or conflicting policies and competing interests, which when recognised could be translated to other countries in South, South-east and East Asia which are still experiencing a slow expansion and inconsistent inclusion of necessary components of HR in their response to the HIV epidemic (Bergenstrom \& AbdulQuader 2010; Dorabjee 2012). 
Table 1: Summary of response types with key features

\begin{tabular}{|c|c|c|c|}
\hline Response & Features & Time & Remarks \\
\hline $\begin{array}{l}\text { Law enforcement } \\
\text { based response }\end{array}$ & $\begin{array}{l}\text { Criminalise IDUs and officially termed them as } \\
\text { "social evil" because of drug use } \\
\text { Forceful detention and compulsory treatment } \\
\text { Centre-based (partly community) } \\
\text { Treatment period two years }\end{array}$ & $\begin{array}{l}\text { Early } \\
1990 \mathrm{~s}\end{array}$ & $\begin{array}{l}\text { MOLISA plays central role } \\
\text { The response ineffective }\end{array}$ \\
\hline $\begin{array}{l}\text { Enhanced law } \\
\text { enforcement } \\
\text { based response }\end{array}$ & $\begin{array}{l}\text { Large scale informational campaign } \\
\text { Mandatory HIV testing } \\
\text { Extended period of treatment } \\
\text { Extended treatment period four years }\end{array}$ & $\begin{array}{l}\text { Late } \\
1990 \mathrm{~s}\end{array}$ & $\begin{array}{l}\text { MOLISA plays central role } \\
\text { Drug problem intensified } \\
\text { with high HIV prevalence } \\
\text { Response ineffective } \\
\text { No strong role of MOH }\end{array}$ \\
\hline $\begin{array}{l}\text { Peer education } \\
\text { based harm } \\
\text { reduction }\end{array}$ & $\begin{array}{l}\text { Low profile peer education ( } 20 \text { provinces) } \\
\text { Pilot harm reduction in some provinces } \\
\text { Challenges and implementation barriers }\end{array}$ & $\begin{array}{l}1993 \text { to } \\
2000\end{array}$ & $\begin{array}{l}\text { Provincial authorities got } \\
\text { support from international } \\
\text { organizations } \\
\text { Maximum duration was pilot } \\
\text { phase }\end{array}$ \\
\hline $\begin{array}{l}\text { Continue } \\
\text { enhanced law } \\
\text { enforcement } \\
\text { based response }\end{array}$ & $\begin{array}{l}\text { Detention and treatment } \\
\text { Option for post rehabilitation and vocational } \\
\text { support } \\
\text { Extended period of treatment up to } 6 \text { years }\end{array}$ & $\begin{array}{l}\text { Early } \\
2000 \mathrm{~s}\end{array}$ & $\begin{array}{l}\text { MOLISA plays central role } \\
\text { Rising HIV prevalence } \\
\text { created scope for MOH role } \\
\text { in the centre } \\
\text { Fail to coordinate with } \\
\text { MOLISA and MPS }\end{array}$ \\
\hline $\begin{array}{l}\text { Harm reduction } \\
\text { based response }\end{array}$ & $\begin{array}{l}\text { Official acceptance through HIV policy } \\
\text { Lack of technical and managerial skills } \\
\text { Poor multi-sectoral collaboration }\end{array}$ & $\begin{array}{l}2004 \text { to } \\
\text { date }\end{array}$ & $\begin{array}{l}\text { Competing with MOLISA } \\
\text { and MOH } \\
\text { Barriers in scale up }\end{array}$ \\
\hline $\begin{array}{l}\text { Policy and public } \\
\text { health based } \\
\text { approach }\end{array}$ & $\begin{array}{l}\text { Creating enabling environment } \\
\text { MMT introduction } \\
\text { Strengthened ART } \\
\text { Compulsory treatment centres still operation } \\
\text { and barriers in accessing HR services } \\
\text { Donor driven programs }\end{array}$ & $\begin{array}{l}2006 \text { to } \\
\text { date }\end{array}$ & $\begin{array}{l}\text { MOH plays central role } \\
\text { Lack effective collaboration } \\
\text { MOLISA and MPS } \\
\text { Compulsory treatment } \\
\text { Funding challenges }\end{array}$ \\
\hline
\end{tabular}

Vietnam has gradually overcome previous policy driven implementation barriers to HR program and successfully reached the stage where interventions are guided by scientific evidence (Nguyen et al. 2010). It has taken more than a decade for official acceptance of HR policies for HIV prevention and drug control, despite the experience of implementing a number of short lived, small-scale projects that appeared to hold out promise for successful continuation after piloting (Quan et al. 1998; UNAIDS \& UNODCCP 2000). The evidence indicates that the participation of IDUs and local communities improved the design and planning of these projects (Walsh et al. 2008). While such pilot interventions did not last beyond the initial phase, the experience and learning derived from them became instrumental at the time of need, when the legal environment started to change towards an expanded HR program with national coverage. Although limited attention was paid to the formal evaluation of these early HR projects, their achievements appear to have been satisfactory (Hammett et al. 2006; Ngo et al. 2009; VAAC/WHO 2009). Later, a unique 'Vietnam HIV Model' was developed to assess the epidemiological and HR impact. This suggests that current programs 
avert between $2 \%$ and $56 \%$ of infections (in selected provinces) among both IDUs and FSWs, depending on the level of program coverage achieved (World Bank 2011). Furthermore, continuing progress in HR programs including condom promotion, needle/syringe and drug substitution through MMT, coupled with the leadership of the central government in the short time after the formal acceptance of HR, has allowed Vietnam to exhibit a significant development in the response to the drug use driven HIV epidemic (AIFOCOM 2010, 2011; Government of Vietnam 2010b; Quan et al. 2008).

Figure 1: Milestones (1991-2013) in HIV \& Drug Response

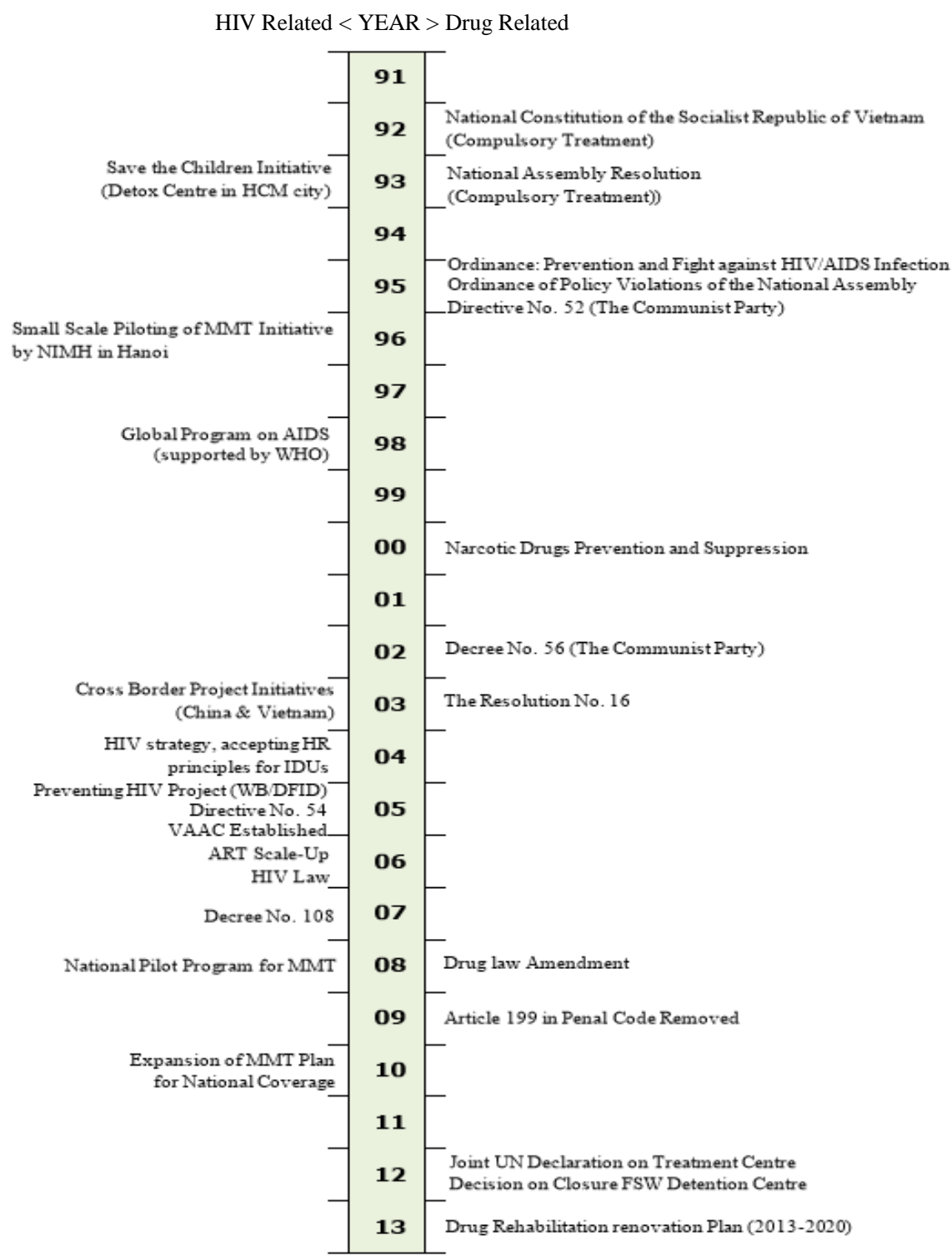


Nevertheless, alongside the present HR program initiatives the traditional drug treatment centre is still operational in parallel through MOLISA and Ministry of Public Security (Edington \& Brayer 2013) and poses enormous challenges at local level such as police have quota and reward system for arresting and sending IDUs to treatment centres, in terms of accessing available HR services for IDUs (Baldwin 2013). In addition, the present HR program needs to be expanded to include IDU subgroups (such as younger, drug injecting FSWs) who often remain out of contact by the HR staff. Fortunately, the opportunity now exists to capitalize on the advantage of the existing favourable legal and policy environment to improve operational issues (such as registration, relapse related policies in MMT management, inclusion, and supportive supervision) associated with HR and MMT program implementation. An effective coordination between the MOH and MOLISA will be required to reach the ambitious country-wide national MMT target to treat 80,000 IDUs by the year 2015 (Baldwin 2013; Edington \& Brayer 2013). As an effective health oriented response to HIV epidemic the testing, counselling and ARV treatment needs to be strengthened further (UNAIDS 2013). The challenges which the IDUs face in timely accessing ARV treatment needs to be addressed (Nguyen et al. 2013) so that treatment initiation precedes the stage of a more advanced HIV infection. Evidence suggest for the treatment and prevention as a combined approach to create an impact on the current epidemic (Kato et al. 2013; Bruce 2013).

Furthermore, Vietnam has yet to deal with the crisis of the compulsory drug treatment centres which still limit access to the existing HR programs and MMT services (Baldwin 2013). Recent reports highlighting serious human rights abuse (Amon et al. 2013; Human Rights Watch 2012) and withdrawal of funding support by international organizations in some Asian countries, pushed the Vietnamese authorities to agree on an internationally accepted solution related to the compulsory drug treatment centres, as well as other conditions, in particular, allowing independent monitoring and basic medical services (Xinema \& Davis 2014). The call for closure of all these centres by joint UN agencies carries significance for urgent policy change (UNAIDS 2012). However, changes in policy relating to these treatment centres is challenging because of different levels of funding support currently they have for these centres (Amon et al. 2014) which undermine the process of closing or converting compulsory treatment centres to voluntary community based centres. As a result, the authorities still struggle to find solutions and ways to respond to the calls for closure of these drug treatment centres by the international community (Baldwin 2013). The decision approved in December, 
2013 showing the renovation plan and scale down the response through drug treatment centre by phases (2013-2020) and thereby did not comply with the international call for closure (Government of Vietnam 2013). Rather the worrying part of the renovation plan continues involvement of MOLISA through at least retaining fifty such treatment centres (Government of Vietnam 2013, Baldwin 2013). This contradiction issues associated with drug, HIV and role of MOLISA need to be settled urgently for the successful achievement in HIV prevention among IDUs. Figure 2 presents the HIV and drug response in Vietnam following two principles such as demand and supply reduction and harm reduction and engagement in advocacy through the national and international organizations to create enabling environment for enhanced prevention.

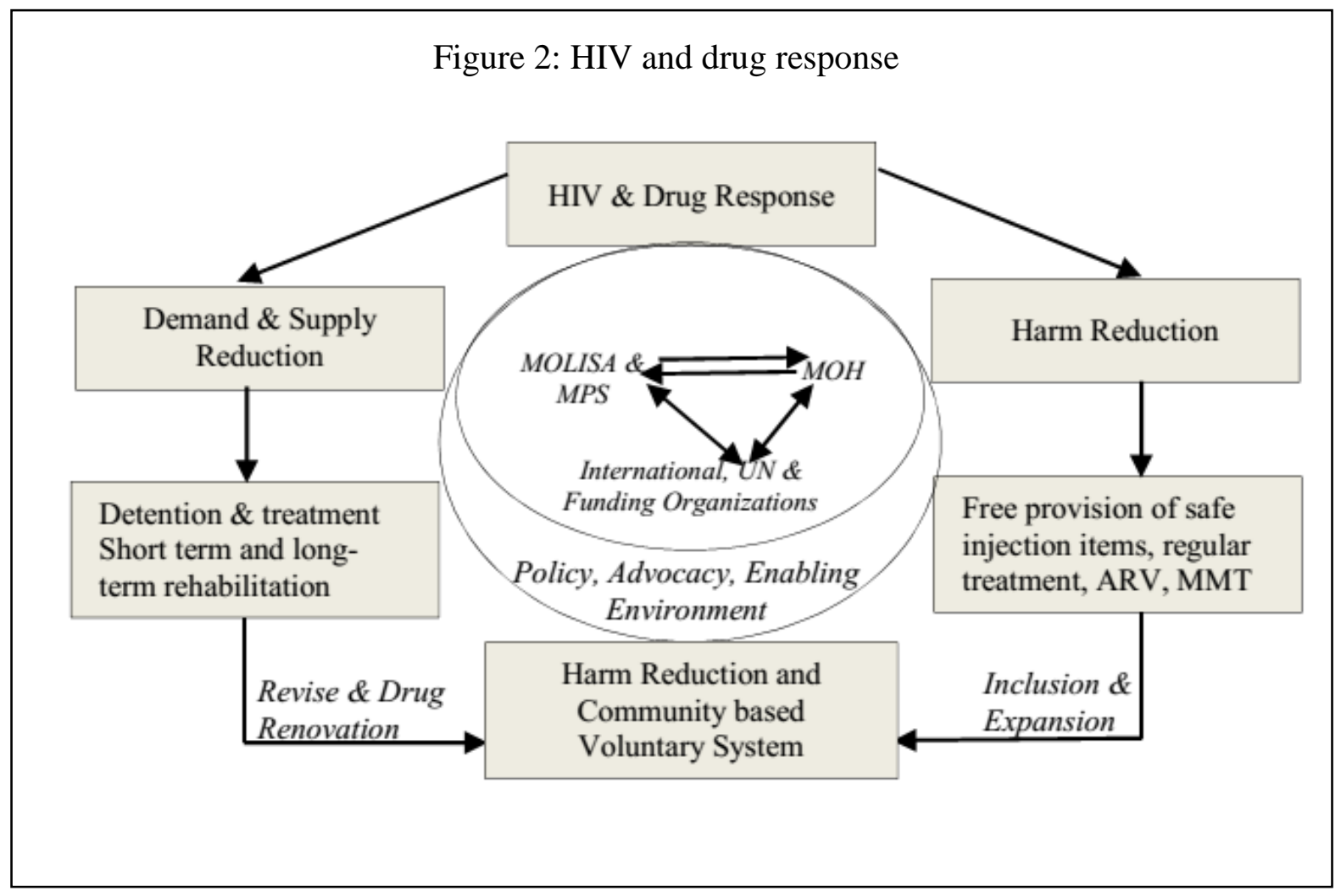

\section{Funding and multi-sectoral collaboration}

There are two other potential barriers, firstly, the decline of external funding and secondly, the lack of a multi-sectoral approach in HIV prevention and drug control, both of which have been identified in terms of sustaining the gains achieved after the formal acceptance of HR principles. The shortfall of funding through international organizations as a result of recent economic development in Vietnam and other economic events such as the global financial crisis, makes the further development of drug and HIV response more difficult. There will 
undoubtedly be an increased challenge in terms of resource allocation for the continuation of HR program with the inclusion of new components. The political leadership and motivation of the Government reflects the commitment to meet the challenge of transitioning towards an effective future response (Government of Vietnam 2011a) and developments, as discussed, in recent years (2011-2013) are promising. The approval of the HIV/AIDS program as a state funded targeted program is of major significance for fund mobilisation through internal mechanism and is expected to facilitate a favourable transition in funding, if the government leadership and political commitment continues. Although funding for the national targeted program will continue until 2015, it allows an interim period to explore both national and international funding opportunities.

Harmonization of policies is essential to achieve progress with a multi-sectoral approach (UNRTF 2010) and Vietnam has significantly improved the legal environment by approving and enacting a number of related policies in a short time which overlap and compete in their interests (Baldwin 2013; Jardine, Thi Nguyen, et al. 2012; Khuat et al. 2012). However, the lack of harmony in some policy documents, such as between the law on HIV and drug control, inhibits a fully effective, multi-sectoral approach (HAARP 2011). Thus, the police acting in the role of 'crime prevention' in drug control and 'health promoters' in HR and the MMT program (Khuat et al. 2012) illustrate this tension. Although the MMT program has been progressing slowly (in terms of set national target), the role of the police in selecting participants and continuing treatment has been questioned in terms of possible discrimination (Jardine, Thi Nguyen, et al. 2012). A regional project that works with police to find the best ways for their effective engagement as one of the core partners in HR rather than a subsidiary organ has started (Crofts 2010). In summary the achievements over policies and responses in Vietnam, over the years, are significant for putting the policies into practice however, local level efforts are required to take the full advantage of decade long policy transformation.

\section{Regional drug free framework}

Another potential area of harmonization arises because of the active participation of Vietnam in a range of international treaties (especially the United Nations) and regional frameworks which, by and large, promote the vision of a 'drug free' nation (HAARP 2011; The Beckley Foundation 2008). A highly restrictive interpretataion of these documents facilitate frequent criminal sanction procedure against IDUs (Edington \& Brayer 2013). Under such treaties and frameworks, the selected countries, including Vietnam, regularly plan and implement a range 
of law enforcement activities to control the drug situation and illegal consumption, which contradict as well as magnify the obstacles in the continuation of national HR programs (AIFOCOM 2010, 2011; Sharma \& Chatterjee 2012). The joint declaration on drug free ASEAN countries since 1998 is one of the key regional documents and annual progress towards its targets is an ongoing challenge in the implementation of HR programs in Vietnam (AIFOCOM 2010, 2011, 2014). Furthermore, it generates mistrust and misunderstanding between IDUs and law enforcement personnel which must be minimised to promote the wider public health aspects of the injection driven HIV epidemic (Hammett et al. 2005). Figure 3 shows the framework and key document which guide the ASEAN drug free objectives and Vietnam initiatives to meet ASEAN drug free objectives. The $\mathrm{MOH}$, as the health agency, must assume a leadership role and take the lead in harmonizing related inconsistencies. At the same time, the need for transferring leadership to the MOH has been observed by the field level implementers to lead the public health based approach in future over the drug and HIV problem in Vietnam (Khuat et al., 2012).

Figure 3: ASEAN Drug Free Initiatives

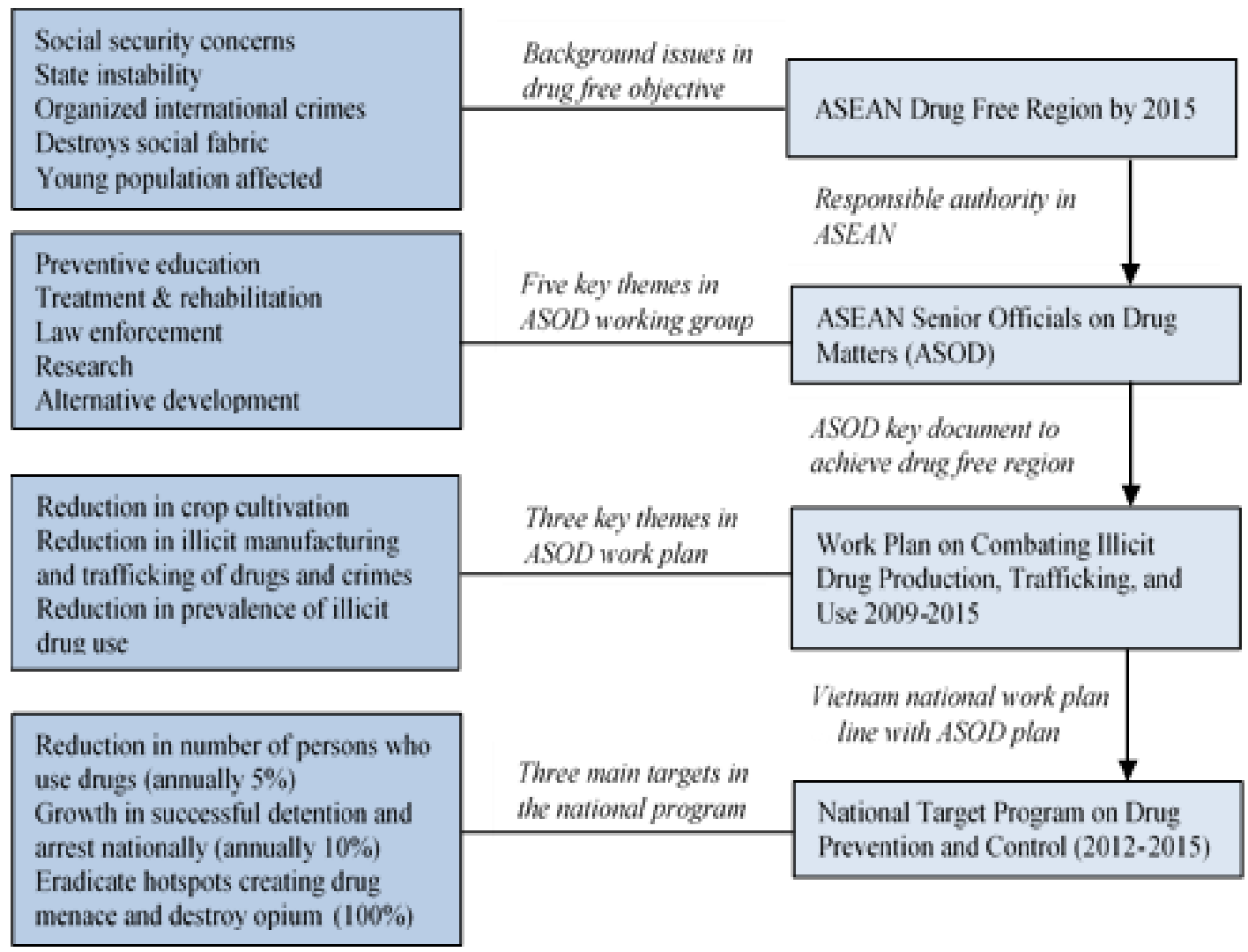




\section{New initiatives and future scope}

Vietnam appears to be receptive to new approaches, for example, the experimental implementation of Treatment 2.0 (Duc et al. 2012), combined ART and MMT scale-up (Tran et al. 2012), and it is expected that there will be more opportunities in the future for broadening HIV prevention through the scope of a multi-sectoral approach. A strong government leadership and political commitment supported by the ongoing advocacy for national HIV program budget should be strengthened for the future of an expanded HR program among IDUs in Vietnam (Baldwin 2013).

\section{Limitation}

We selected important policy documents related to HIV and drug issues to focus the responses and link with the experience emerged from the implementation practice at early stage. However, there could be other documents which might have limited influence on responses which were not included. Similarly this overview reflects the most important aspects of responses towards HIV and drug such as needle/syringe and condom distribution, medication assisted substitution, ARV treatment. Other issues relating civil society involvement, gender roles, social stigma, and health sector response to HIV/AIDS which could influence existing responses were not included. Despite this limitation, our review encompasses important aspects of policies and responses and incorporates a great deal of information to present a complete evolvement of HIV and drug response in Vietnam. Furthermore, the insights, lessons and way forward regarding the policies and responses towards drug use driven HIV epidemic in Vietnam presented in this overview will be instrumental to develop a substantial response in future. The prudent utilisation of our findings in upcoming days by the local, national and international policy and program planners would help minimise current contradictions and promote multi-sectoral partnership to implement current response comprehensively among IDUs in Vietnam.

\section{Conclusion}

The transformation of drug and HIV policies in Vietnam, over the years has supported favourable responses towards injection driven HIV epidemic. However, further challenges are ahead to sustain the gains achieved as a result of such policy transformation. This review has highlighted some key features relating drug and HIV which highlight: political 
commitment and government leadership as essential for a long-term strategy; supportive policies and a continuous resource allocation that work altogether to progress a substantial response regarding the HIV epidemic among IDUs. The government of Vietnam should continue investing in the evidence-based innovative programs by mobilising resources in future which will in turn help stabilise the epidemic and reduce HIV infection. Consequently, the risk of a worsening epidemic situation will be minimised by promoting a positive impact and well-being among the IDUs. The authorities in Vietnam along with the international community should be prepared to engage actively in the above identified policy issues including: continue political commitment, strengthen government leadership, foster multisectoral collaboration, and ensure a continuous national resource allocation. In summary urgent mitigation in policy contradictions relating HR program accessibility and implementation of drug detention centres, law enforcement activities to support regional drug free objectives, and future allocation of internal resources for national programming should be prioritised. Government leadership and commitment will be crucial in order to develop a substantial HIV prevention response for the IDUs which will create an impact on the injecting drug use driven HIV epidemic in Vietnam.

\section{Conflict of interest}

The authors declare no conflicts of interest.

\section{Acknowledgement}

The first author is a $\mathrm{PhD}$ candidate in Griffith University, Queensland, Australia and acknowledges the financial support of Australia Awards. He also acknowledges the assistance of Vietnam Authority of HIV/AIDS Control. 


\section{References}

Abdul-Quader, Abu S., Vu Minh Q., \& O'Reilly, Kevin. (1999). A tale of two cities: HIV risk behavioiurs among injecting drug users in Hanoi and Ho Chi Minh City, Vietnam. Drug and Alcohol Review, 18(4), 401-401.

Ahmed, Tanvir., Nguyen, Long T., Huong, Phan T., Lee, Patricia C. T., \& Stewart, Donald E. (2014). HIV Risk Behaviours among Injecting Drug Users in Vietnam: A Review. Science Journal of Public Health, 2(3), 209-215. doi: 10.11648/j.sjph.20140203.22

AIFOCOM. (2010). ASEAN Inter-Parliamentary assembly report of the seventh meeting of the AIPA fact-finding committee (AIFOCOM) to combat the drug menace.

AIFOCOM. (2011). ASEAN Inter-Parliamentary assembly report of the eighth meeting of the AIPA fact-finding committee (AIFOCOM) to combat the drug menace.

AIFOCOM. (2014). ASEAN Inter-Parliamentary assembly report of the eleventh meeting of the AIPA fact-finding committee (AIFOCOM) to combat the drug menace.

Amon, Joseph J., et al. (2013). Compulsory drug detention centers in China, Cambodia, Vietnam, and Laos: Health and human rights abuses. Health and Human Rights, $15(2), 124-137$.

Amon, Joseph J., et al. (2014). Compulsory drug detention in East and Southeast Asia: Evolving government, UN and donor responses. International Journal of Drug Policy, 25(1): 13-20.

Asia News Monitor. (2010). Vietnam: Vietnam steps up methadone treatment for heroin $\begin{array}{lll}\text { addicts. } & \text { Retrieved } & \text { from }\end{array}$ http://search.proquest.com.libraryproxy.griffith.edu.au/docview/1018452751?accounti $\mathrm{d}=14543$

Baldwin, Simon. (2013). Drug policy advocasy in Asia: Challenges, opportunities and prospects. IDPC Report. International Drug Policy Consortium. 
BBC Monitoring Asia Pacific. (2005). WHO official praises Vietnam's HIV/AIDS strategy, BBC Monitoring Asia Pacific, pp. 1-1. Retrieved from http://search.proquest.com.libraryproxy.griffith.edu.au/docview/461036137?accountid $=14543$

Bergenstrom, Anne M., \& Abdul-Quader, Abu S. (2010). Injection drug use, HIV and the current response in selected low-income and middle-income countries. AIDS, 24( Supplement 3), S20-29. doi: 10.1097/01.aids.0000390086.14941.91

Beyrer, Chris. Razak, Myat H., Lisam, Khomdom Chen, Jie, Lui, Wei., \& Yu, Xiao-Fang. (2000). Overland heroin trafficking routes and HIV-1 spread in south and south-east Asia. AIDS, 14(1), 75-83.

Brownson, Ross. C., Chriqui, Jamie F., \& Stamatakis, Katherine A. (2009). Understanding evidence-based public health policy. Americal Journal of ublic Health, 99(9). 15761583.

Bruce, Douglas R. (2013). Is it time for treatment as prevention among people who inject drug? Journal of Acquired Immune Deficiency Syndromes, 63(5), 545-547.

Chung, A., Vu, Minh Q., \& Dondero, Timothy J. (1998). HIV epidemiologic situation in Vietnam: A review of available data. AIDS, (12 Supplement B), S43-49.

Cohen, John. (2003). HIV and heroin: A deadly international affair: Vietnam. Science, 301(5640), 1657-1658. doi: 10.1126/science.301.5640.1657

Communist Party of Vietnam. (2005). Directive No. 54 of the party central committee's secretariat: Strengthening the leadership in HIV/AIDS prevention and control in new situation. Hanoi, Vietnam.

Crofts, Nick. (2010). Engaging with police in prevention of HIV among and from injecting drug users. Journal of Practice Medicine, Vietnam Ministry of Health, 742-743(74), $311-312$ 
Crofts, Nick., Costigan, Genevieve, Narayanan, Palani, Gray, Jennifer, Dorabjee, Jimmy, Langkham, B., . . . Deany, Paul. (1998). Harm reduction in Asia: A successful response to hidden epidemics. The Asian Harm Reduction Network. AIDS, 12 (Supplement B), S109-115.

DEA. (2003). Drug intelligence brief: Vietnam country brief. Washington, DC.

Des Jarlais, Don. C., Kling, Ryan, Hammett, Theodore. M., Ngu, Doan, Liu, Wei., Chen, Yi., . . . Friedmann, Patricia. (2007). Reducing HIV infection among new injecting drug users in the China-Vietnam cross border project. AIDS, 21 (Supplement 8), S109-114. doi: 10.1097/01.aids.0000304705.79541.34

Devaney, M., Reid, Garry, \& Baldwin, Simon. (2006). Situational analysis of illicit drug issues and responses in the Asia-Pacific region. Canbera, Australia. Retrieved from ANCD research paper.

Dorabjee, Jimmy. (2012). Harm reduction in South, South East and East Asia. In R. Pates \& D. M. Riley (Eds.), Harm reduction in substance use and high-risk behaviour international policy and practice (First ed., pp. 354-369). Chichester, West Sussex: Wiley-Blackwell.

Duc, Duong B., Fabio, Mesquita, Thi Nhan, D., Masaya, Kato., Thi Thuy Van, Nguyen., Thi Minh Thu, Nguyen, \& Adrienne, Poon. (2012). Treatment 2.0 pilot in Vietnam—early progress and challenges. World Journal of AIDS, 2(2), 64-70.

Edington, Claire. \& Ronald, Bayer. (2013). When grammars collide: Harm reduction, drug detention and the challenges of international policy reform efforts in Vietnam. Glob Public Health, 8(Supplementary 1), S75-91.

Government of Vietnam. (2002). Decree no. 56/2002/ND-CP of May 15, 2002 on the organization of the family or community-based rehabilitation Hanoi, Vietnam. 
Government of Vietnam. (2004). Decision No. 36/2004/QD-TTg of March 17, 2004 approving the national strategy on HIV/AIDS prevention and control in Vietnam till 2010 with a vision to 2020. Hanoi. Vietnam.

Government of Vietnam. (2005). Decision 432/QD-TTg Establishment of the Viet Nam Administration of HIV/AIDS Control under the Ministry of Health. Hanoi, Vietnam.

Government of Vietnam. (2007). Government's Decree No. 108/2007/ND-CP of June 26, 2007: Detailing the implementation of a number of articles of the law on HIV/AIDS prevention and control Hanoi, Vietnam.

Government of Vietnam. (2010a). Decision 32/2010QD-TTg: Approving the scheme on the development of the social work profession during 2010-2020 Hanoi, Vietnam.

Government of Vietnam. (2010b). The Socialist Republic of Vietnam: Declaration of Commitment on HIV and AIDS adopted at the 26th United Nations General Assembly Special Session in June 2001 (UNGASS).

Government of Vietnam. (2011a). Conclusion 84/TB-VPCP, Deputy Prime Minister Nguyen Xuan Phuc in the final meeting on HIV / AIDS, Drugs and Prostitution in 2011 and tasks in 2012. Hanoi. Vietnam.

Government of Vietnam. (2011b). Decision 1001/QD-TTg on national strategy on drug control, 2011. Hanoi. Vietnam.

Government of Vietnam. (2012). Viet Nam AIDS response progress report 2012: Following up the 2011 political declaration on HIV/AIDS. Hanoi, Vietnam.

Government of Vietnam. (2013). Decision 2596/QD-TTg on drug rehabilitation renovation plan 2013-2020. Hanoi. Vietnam.

HAARP. (2011). Law and Policy Review. AusAID.

Hammett, Theodore. M., Bartlett, Nicholas, A., Chen, Yi, Ngu, Doan, Cuong, Doa D., Phuong, Nguyen M., . . . Des Jarlais, Don C. (2005). Law enforcement influences on 
HIV prevention for injection drug users: Observations from a cross-border project in China and Vietnam. International Journal of Drug Policy, 16(4), 235-245

Hammett, Theodore M., Des Jarlais, Don, Johnston, P., Kling, Ryan, Ngu, D., Liu, Wei, .. . Donghua, M. (2007). HIV prevention for injection drug users in China and Vietnam: Policy and research considerations. Global Public Health, 2(2), 125-139. doi: $10.1080 / 17441690600981806$

Hammett, Theodore M., Kling, Ryan, Johnston, Patrick, Liu, Wei., \& et al. (2006). Patterns of HIV prevalence and HIV risk behaviors among injection drug users prior to and 24 months following implementation of cross-border HIV prevention interventions in northern Vietnam and southern China. AIDS Education and Prevention, 18(2), 97-115

Hammett, Theodore M., Wu, Zunyou, Duc, Tran T., Stephens, David Sullivan, Sheena, Liu, Wei., ... Des Jarlais, Don C. (2008). 'Social evils' and harm reduction: The evolving policy environment for human immunodeficiency virus prevention among injection drug users in China and Vietnam. Addiction, 103(1), 137-145. doi: 10.1111/j.13600443.2007.02053.x

Hien, Nguyen T. \& Wolffers, Ivan. (1994). HIV infection in Vietnam, The Lancet, pp. 410.

Hien, Nguyen T., Giang, Le T., Binh, Phan N., Deville, Walter, van Ameijden, Erik. J., \& Wolffers, Ivan. (2001). Risk factors of HIV infection and needle sharing among injecting drug users in Ho Chi Minh City, Vietnam. Journal of Substance Abuse, 13(1-2), 45-58.

Hien, N. T., Giang, Le T., Binh, Phan N., \& Wolffers, Ivan. (2000). The social context of HIV risk behaviour by drug injectors in Ho Chi Minh City, Vietnam. AIDS Care, 12(4), 483-495. doi: 10.1080/09540120050123882 
Human Rights Watch (2011). Vietnam The Rehab Archiepelago. Forced labor and other abuses in drug detention centres in southern Vietnam. New York, Human Rights Watch.

Human Rights Watch (2012). Torture in the name of treatment: Human Rights abuses in Vietnam, China, Combodia, and Lao PDR. New York, Human Rights Watch.

IHRD. (2008). Harm reduction program developments: Countries with injection-driven HIV epidemics. New York: Open Society Institute.

Institute of Medicine. (2005). Preventing HIV infection among injecting drug users in high risk countries: An assessment of the evidence: National Academies Press.

Jardine, Melissa, Crofts, Nick, Monaghan, Geoff, \& Morrow, Martha. (2012). Harm reduction and law enforcement in Vietnam: Influences on street policing. Harm Reduction Journal, 9(1), 27. doi: 10.1186/1477-7517-9-27

Jardine, Melissa, Thi Nguyen, Van. A., \& Khuat, Thu H. (2012). Case study: Methadone maintenance treatment in Hanoi, Vietnam. Harm Reduction Journal, 9(1), 26. doi: $10.1186 / 1477-7517-9-26$

Kato, M., Granich, R., Bui, Duck D., Tran, H. V., Nadol, P., Jacka, D. et al. (2013). The potential impact of expanding antiretroviral therapy and combination prevention in Vietnam: Towards elimination of HIV transmission. Journal of Acquired Immune Deficiency Syndromes, 63(5):e142-9.

Khoat, Dang.V., West, Garry R., Valdiserri, Ronald O., \& Phan, Ngoc T. (2003). Peer education for HIV prevention in the socialist republic of Vietnam: A national assessment. Journal of Community Health, 28(1). 1-17.

Khuat, Thu H., Nguyen, Van A., Jardine, Melissa., Moore, Timothy, Bui, Thu H., \& Crofts, Nick. (2012). Harm reduction and "clean" community: Can Viet Nam have both? Harm Reduction Journal, 9, 25. doi: 10.1186/1477-7517-9-25 
Khuat, Thu H. O. (2007). HIV/AIDS policy in Vietnam. A civil society perspective. New York: Open Society Institute.

Le Truong, G., Nguyen Thanh, S., Le Thuy Lan, T., Vu, L., Esther Sid, H., \& Lindan, C. (2000). Evaluation of STD/HIV prevention needs of low- and middle-income female sex workers in Ho Chi Minh City, Vietnam. AIDS and Behavior, 4(1), 83-83.

Lindan, C. P., Lieu, T. X., Giang, L. T., Lap, V. D., Thuc, N. V., Thinh, T., . . Mandel, J. S. (1997). Rising HIV infection rates in Ho Chi Minh City herald emerging AIDS epidemic in Vietnam. AIDS, 11 (Supplment 1), S5-13.

Long, Nguyen T., Manh, Pham D., Tam, Nguyen T. M., Huynh, Nguyen T., Hoang, Tran V., Nhu, Nguyen T., . . Cong, Van V. (2010). Summary of the major findings from an evaluation of the pilot methadone maitenance therapy program in Vietnam. Journal of Practice Medicine, Vietnam Ministry of Health, 742-743(74), 332-334.

Maher, Lisa. (2004). Entwined epidemics: HIV and injecting drug use in Vietnam. International Journal of Drug Policy, 15(3), 169-170

Maher, Lisa, Coupland, Heidi, Musson, Rachel. (2007). Scaling up HIV treatment, care and support for injecting drug users in Vietnam. International Journal of Drug Policy, 18(4). 296-305.

Marlatt, Alan G., (Ed.). (1998). Harm reduction: Pragmatic strategies for managing high risk behaviors. Guilford Press: New York.

McCoy, Alfred W. (1991). The politics of heroin: CIA complicity in the global drug trade. Brooklyn, NewYork: Lawrence Hill Books.

Ministry of Health. (2011). Results from the HIV/STI integrated biological and behavioral surveillance (IBBS) in Vietnam -(R ound II) 2009. Hanoi, Vietnam: National Institute of Hygiene and Epidemiology and Family Health International. 
Morales, John A. (2013). The 'middle-income effect' on HIV/AIDS program in Vietnam. DEVEX The Development Newswire Retrieved from https://www.devex.com/news/the-middle-income-effect-on-hiv-aids-programs-invietnam-81491 on 17 June, 2014.

National Assembly of Vietnam. (2009). The amended penal code of Vietnam. Hanoi, Vietnam.

Ngo, Anh D., Schmich, Lucina, Higgs, Peter, \& Fischer, Andrea. (2009). Qualitative evaluation of a peer-based needle syringe programme in Vietnam. International Journal of Drug Policy, 20(2), 179-182. doi: 10.1016/j.drugpo.2007.12.009

Nguyen, Duc B., Do, Nhan T., Shiraishi, Ray W., Le, Yen N., Tran, Quang H., Nguyen, Hai H., et al. (2013). Outcomes of antiretroviral therapy in Vietnam: results from a national evaluation. PLoS One. 8(2). e55750.

Nguyen, Ha P., Pharris, Anastasia, Huong, Nguyen T., Chuc, Nguyen T., Brugha, Ruairi \& Thorson, Anna. (2010). The evolution of HIV policy in Vietnam: From punitive control measures to a more rights-based approach. Global Health Action, 3. doi: 10.3402/gha.v3i0.4625

Nguyen, Tran H., Hoang, Thuy L., Pham, Kim C., van Ameijden, Erik J., Deville, Walter \& Wolffers, Ivan. (1999). HIV monitoring in Vietnam: System, methodology, and results of sentinel surveillance. Journal of Acquired Immunno Deficiency Syndromes, 21(4), 338-346

Nguyen, Tran H., Nguyen, Thanh L., \& Trinh, Quan H. (2004). HIV/AIDS epidemics in Vietnam: Evolution and responses. AIDS Education and Prevention, 16(3 Supplement A), 137-154. doi: 10.1521/aeap.16.3.5.137.35527 
Nguyen, Tam T., Nguyen, Thanh L., Pham, Manh D., Vu, Hoang H., \& Mulvey, Kevin P. (2012). Methadone maintenance therapy in Vietnam: An overview and scaling-up plan. Advances in Prevebtive Medicne, 2012, 732484. doi: 10.1155/2012/732484

Nguyen, Van T., \& Scannapieco, Maria. (2008). Drug abuse in Vietnam: A critical review of the literature and implications for future research. Addiction, 103(4), 535-543. doi: 10.1111/j.1360-0443.2007.02122.x

Poshyachinda, V. (1993). Drug injecting and HIV infection among the population of drug abusers in Asia. Bulletin of Narcctics, 45(1), 77-90.

Quan, Vu M., Chung, A., \& Abdul-Quader, Abu S. (1998). The feasibility of a syringeneedle-exchange program in Vietnam. Substance Use \& Misuse, 33(5), 1055-1067.

Quan, Vu M., Chung, A., Long, Hoang T., \& Dondero, Timothy J. (2000). HIV in Vietnam: The evolving epidemic and the prevention response, 1996 through 1999. Journal of Acquired Immuno Deficiency Syndromes, 25(4), 360-369.

Quan, Vu M., Hien, Nguyen T., \& Go, Vivian F. (2008). The HIV epidemic in Vietnam: Past, present, and opportunities. In D. D. Celentano, C. Beyrer \& I. ebrary (Eds.), Public health aspects of HIV/AIDS in low and middle income countries: Epidemiology, prevention and care (pp. 457-579). New York: Springer.

Reid, Garry, \& Costigan, Genevieve. (2002). Revisiting the hidden epidemic: A situation assessment of drug use in Asia in the context of HIV/AIDS. Australia: Burnet Institute. Centre for Harm Reduction.

Reid, Garry, \& Higgs, Peter. (2011). Vietnam moves forward with harm reduction: An assessment of progress. Global Public Health, 6(2), 168-180. doi: $10.1080 / 17441690903527314$

Rekart, M. L. (2002). Sex in the city: Sexual behaviour, societal change, and STDs in Saigon. Sexually Transmitted Infections, 78 Supplement 1, i47-54. 
Sharma, Mukta., \& Chatterjee, Anindya. (2012). Partnering with law enforcement to deliver good public health: The experience of the HIV/AIDS Asia regional program. Harm Reduction Journal, 9(1), 24. doi: 10.1186/1477-7517-9-24

Tarantola, D., Hoat, L., Whelan, A., Wright, P., Xuan, L., Huong, L., . . . Do, T. (2009). HIV/AIDS rehabilitation centres in Vietnam: Sexual and reproductive health needs, care and choices of current and former detainees and their sexual partners. A review of the literature. Technical Series Paper \# 09.1.

The Beckley Foundation. (2008). Recalibrating the regime: The need for a human rightsbased approach to international drug policy.

The National Assembly of Vietnam. (1992). Constitution of the Socialist Republic of Vietnam (As Amended 25 December 2001) (Vol. Article 61).

The National Assembly of Vietnam. (1993). Resolution 06/CP on strengthening drug control and prevention.

The National Assembly of Vietnam. (1995). Ordinance on the prevention and fight against HIV/AIDS infection. Hanoi, Vietnam.

The National Assembly of Vietnam. (2000a). Decision no. 150/2000/QD-TTg of December 28, 2000 approving the action program for drug prevention and combat for the 20012005 period. Hanoi, Vietnam.

The National Assembly of Vietnam. (2000b). The law of drug prevention and fight. Hanoi, Vietnam.

The National Assembly of Vietnam. (2003). Resolution No. 16/2003NQ-QH11 on Implementation and management of organization of vocational tranining, and employment for the drug addiction treatment in Ho Chi Minh City and some others selected citities. Hanoi, Vietnam. 
Tran, Bach X., Ohinmaa, Arto, Duong, Anh T., Nguyen, Thanh L, Vu, Phu X., Mills, Stese, . . . Jacobs, Philip. (2012). Cost-effectiveness of integrating methadone maintenance and antiretroviral treatment for HIV-positive drug users in Vietnam's injection-driven HIV epidemics. Drug and Alcohol Depend, 125(3), 260-266. doi: 10.1016/j.drugalcdep.2012.02.021

UNAIDS. (2011). Vietnam country review December 2011: At a glance. Hanoi, Vietnam.

UNAIDS. (2013). UNAIDS report on the global AIDS epidemic 2013. UNAIDS, Geneva. Switzerland.

UNAIDS. (2012). Joint statement: Compulsory drug detention and rehabilitation centres. UNAIDS, Geneva. Switzerland.

UNAIDS. (2012). WHO UNODC UNAIDS technical guide for countries to set targets for universal access to HIV prevention, treatment and care for injecting drug users. 2012 revision. WHO, Geneva. Swuitzewrland.

UNAIDS \& UNODCCP. (2000). Drug use and HIV vulnerability: Policy research study in Asia. Bangkok, Thailand: UNAIDS.

UNODC. (2003). EthnicMinorities, drug use and harm in the highlands of northern Vietnam: A contextual analysis of the situation in six communes from Son la, Lai Chau and Lao Cai. Hanoi, Vietnam.

UNODC. (2005). Country profile: Vietnam country profile. Hanoi, Vietnam: UNODC.

UNRTF. (2010). Harm reduction in Asia: Progress towards universal access to harm reduction services among people who inject drugs. Australia: Burnet Institute.

VAAC/WHO. (2009). Good practice in Asia: Targeted HIV prevention for injecting drug users and sex workers. Hanoi, Vietnam: WHO.

Vietnam Commission for Population Family and Children. (2007). HIV/AIDS in Vietnam: The current situation, the national response, the emerging challenges. Hanoi. 
Vu, Tran. (2001). Harm reduction for injecting drug users in Vietnam: A situation assessment. Victorian Public Health Tranining Scheme: Australia.

Vuong, Thu, Ali, Robert, Baldwin, Simon, \& Mills, Steve. (2012). Drug policy in Vietnam: A decade of change? International Journal of Drug Policy, 23(4), 319-326. doi: 10.1016/j.drugpo.2011.11.005

Walt, Gili. \& Gilson, Lucy. (1994). Reforming the health sector in developing countries: The central role of policy analysis. Health Policy and Planning, 9(4). 353-370.

Walsh, Nick, Gibbie, Tania M., \& Higgs, Peter. (2008). The development of peer educatorbased harm reduction programmes in Northern Vietnam. Drug and Alcohol Review, 27(2), 200-203. doi: 10.1080/09595230701829348

WHO. (2005). Vietnam: Summary country profile for HIV/AIDS treatment scale-up Hanoi, Vietnam.

WHO. (2009). Assessment of compulsory treatment of people who use drugs in Cambodia, China, Malaysia and Vietnam: An application of selected human rights principles. Western Pacific Region: World Health Organization.

Wodak, Alex. (2006). Lessons from the first international review of the evidence for needle syringe programs: The band still plays on. Substance Use \& Misuse, 41(6-7), 837839. doi: $10.1080 / 10826080600669587$

World Bank. (2011). Evaluation of epidemiological impact of harm reduction programs on HIV in Vietnam. Hanoi, Vietnam: World Bank.

Ximena, Navia Henao and Sara L. M. Davis (2014). Compulsory drug detention in East and Southeast Asia: Response from the Global Fund to Fight AIDS, Tuberculosis and Malaria. International Journal of Drug Policy, 25(1): 21. 